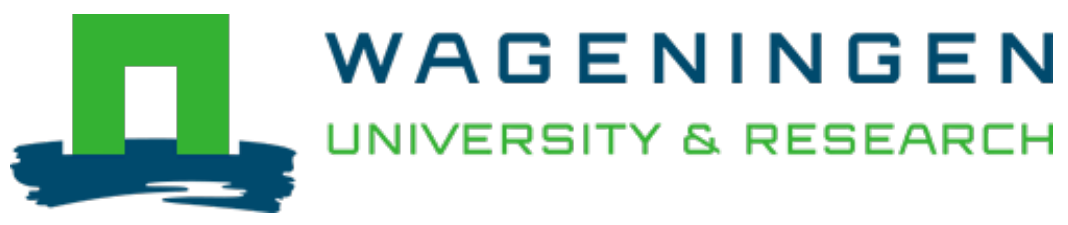

\author{
Barriers to the adoption and diffusion of technological innovations for climate- \\ smart agriculture in Europe: evidence from the Netherlands, France, Switzerland \\ and Italy \\ Journal of Cleaner Production \\ Long, T.B.; Blok, V.; Coninx, I. \\ https://doi.org/10.1016/j.jclepro.2015.06.044
}

This article is made publicly available in the institutional repository of Wageningen University and Research, under the terms of article $25 \mathrm{fa}$ of the Dutch Copyright Act, also known as the Amendment Taverne. This has been done with explicit consent by the author.

Article 25 fa states that the author of a short scientific work funded either wholly or partially by Dutch public funds is entitled to make that work publicly available for no consideration following a reasonable period of time after the work was first published, provided that clear reference is made to the source of the first publication of the work.

This publication is distributed under The Association of Universities in the Netherlands (VSNU) 'Article $25 \mathrm{fa}$ implementation' project. In this project research outputs of researchers employed by Dutch Universities that comply with the legal requirements of Article 25fa of the Dutch Copyright Act are distributed online and free of cost or other barriers in institutional repositories. Research outputs are distributed six months after their first online publication in the original published version and with proper attribution to the source of the original publication.

You are permitted to download and use the publication for personal purposes. All rights remain with the author(s) and / or copyright owner(s) of this work. Any use of the publication or parts of it other than authorised under article $25 \mathrm{fa}$ of the Dutch Copyright act is prohibited. Wageningen University \& Research and the author(s) of this publication shall not be held responsible or liable for any damages resulting from your (re)use of this publication.

For questions regarding the public availability of this article please contact openscience.library@wur.nl 


\title{
Barriers to the adoption and diffusion of technological innovations for climate-smart agriculture in Europe: evidence from the Netherlands, France, Switzerland and Italy
}

\author{
Thomas B. Long ${ }^{\mathrm{a},{ }^{*}}$, Vincent Blok ${ }^{\mathrm{a}}$, Ingrid Coninx ${ }^{\mathrm{b}}$ \\ ${ }^{a}$ Wageningen University, The Netherlands \\ ${ }^{\mathrm{b}}$ Alterra Wageningen UR, The Netherlands
}

\section{A R T I C L E I N F O}

\section{Article history:}

Received 16 March 2015

Received in revised form

8 June 2015

Accepted 10 June 2015

Available online xxx

\section{Keywords:}

Climate change

Agriculture

Climate-smart agriculture

Technological innovation

Innovation adoption

\begin{abstract}
A B S T R A C T
Climate-smart agriculture (CSA) is one response to the challenges faced by agriculture due to climate change. As with other sustainability transitions, technological innovation is highlighted as playing a critical role, however, the adoption and diffusion of technological innovations in OECD countries is slow. The aim of this paper is to identify key socio-economic barriers, in terms of supply and demand, that inhibit the adoption and diffusion of CSA technological innovations in Europe. To achieve this aim, a theoretical framework is constructed based on a literature review of socio-economic barriers effecting adoption and diffusion. This framework is explored with data from semi-structured interviews with CSA technology providers and members of agricultural supply chains, such as farmers associations and consumer goods producers (the end-users of the technology). Data was collected on the barriers they experienced, with interviews conducted in the Netherlands, France, Switzerland and Italy. This data was thematically coded and categorised to identify key barrier typologies. The results demonstrate that barriers exist on both the demand (user) and supply (technology provider) sides. The paper provides recommendations for increasing the adoption and diffusion of CSA technological innovations, as well as implications for the CSA and innovation literature.
\end{abstract}

๑) 2015 Elsevier Ltd. All rights reserved.

\section{Introduction}

Climate change has been the focus of action for over two decades by governments, since the signing of the United Nations Framework Convention on Climate Change in 1992, and increasingly since the late 1990's by business (Kolk et al., 2008). Agriculture in particular will be subjected to profound challenges due to climate change, having to adapt to changing weather patterns, contribute towards greenhouse-gas (GHG) emission reductions. Whilst facing these challenges, an increasing world population will require feeding. Climate-smart agriculture (CSA) is highlighted as key response to these challenges, seeking to enhance agricultural productivity, promote adaptation and enable GHG emission reductions.

Technological innovation has been a key response to sustainability challenges, including climate change (EIT, 2014; European

\footnotetext{
* Corresponding author.

E-mail address: tomblong9@aol.com (T.B. Long).
}

Commission, 2014a; Morand and Barzman, 2006). As such, technological innovation, through the concept of CSA, represents one response to the challenges faced by agriculture.

As highlighted above, agriculture will be profoundly affected by climate change. Agriculture is a significant sector in terms of GHG emissions, and so will face pressure to mitigate climate change through GHG emission reductions. The 2014 Fifth Assessment Report by the Intergovernmental Panel on Climate Change (IPCC) estimated current emissions from agriculture, forestry and other land use is responsible for around a quarter of anthropogenic GHG emissions (Smith et al., 2014). Agriculture contributes around 11\% according to the United National Environment Programme (UNEP) (2013). If pre-and post-process emissions are included, global food systems contribute between $19 \%$ and $29 \%$ of global GHG emissions (Vermeulen et al., 2012). The potential for GHG emission reductions from agriculture up to 2030, through reductions in GHG emissions and increases in soil sequestration are estimated to be between 4500 and $6000 \mathrm{Mt} \mathrm{CO} 2$ e/year (Branca et al., 2013; Smith et al., 2008). This mitigation will present multiple constraints for agriculture, as methane, $\mathrm{N}_{2} \mathrm{O}$ and $\mathrm{CO}_{2}$ are linked to fuel and electricity 
use, but are also produced through fertiliser production, ruminants and land-use changes.

Further, under current projections, in order to feed the global population in 2050 , food production must increase by $70 \%$; previous yield increases have often been gained through the use of fossils fuels, creating further urgency with regards to GHG emission levels due to agriculture. This implies that future increases must find climate-smart methods and inputs (Bogdanski, 2012). Whilst facing these challenges, agriculture must also deal with increasing weather variability and unpredictability, affecting the resilience of our food production systems (Bogdanski, 2012; Nelson et al., 2009). Climate change is expected to lead to greater variability in weather patterns, with increases in the occurrence and severity of extreme weather such as flood, storms, droughts or heat waves, which can all negatively impact on agriculture (Coumou et al., 2014; Trnka et al., 2014); whilst many impacts are expected to be negative, some areas will experience positive side-effects from climate change (European Commission, 2015). Local through to continental production patterns and methods are likely to change due to such impacts.

Developing counties in particular are vulnerable to climate change impacts. This is due to the relative importance of the agricultural sector and generally greater vulnerability to climate change impacts within these contexts. The impacts of climate change on agriculture threatens the economic development of such countries, and the welfare of their populations (FAO and EU, 2014). Due to these reasons, much research is evident on agriculture and climate change within developing nation contexts, and specifically in terms of CSA (Arslan et al., 2013; Bogdanski, 2012; Branca et al., 2011; Eidt et al., 2012).

CSA is one response to these challenges, which seeks to achieve sustainable agricultural development for food security under climate change impacts (FAO, 2013). CSA strives for three objectives. These include sustainable increases of agricultural productivity and incomes, the adaptation and building of resilience to climate change impacts and the reduction of GHG emissions where possible. This creates three distinct 'pillars', and potentially a 'triple-win' (FAO, 2014). CSA can be considered a programmatic concept, acting between knowledge and policy. CSAs overarching aim is to orientate and 'ground' the correct technical, policy and investment conditions required for agriculture to respond to climate change and future food demands (Ren, 2015). A key reason for the emergence of the concept was the recognition that agriculture, and related food security issues, require a synthesised approach which may not be achieved by tackling climate mitigation and adaptation objectives separately.

In the European Union climate change is high on the agricultural policy agenda, due to expectations that climate change will affect the main resources of farmers, including for example water resources and soil quality (Commission of the European Communities, 2009). Given the economic and social importance of the agricultural sector, the European Commission has developed strategies to urge member states towards (concerted) action, including 'climate-proofing' at the EU level as well as better informed decision-making (European Commission, 2014b). Preventive actions are encouraged, with the Common Agricultural Policy (CAP) being at the core of the agricultural transition, encouraging member states to embed climate change in their regional rural development programs (Commission of the European Communities, 2009). To enable changes on the ground, these policies will assist European farmers in the modernisation of farms and to adapt management practices by offering training, compensations, advisory services and technological and management innovations (European Commission, 2015).
Technological innovations, often originating from 'start-ups' or established technology companies, have been highlighted as playing a central role in transitions to a sustainable future, including within the context of CSA. Indeed, CSA technological innovations are already on the market in many cases, as illustrated within Fig. 1 and Table 2. However, diffusion curves predict that initial adoption rates of CSA technological innovations will be slow (Kemp and Volpi, 2008), as is the case with technological innovations more generally in countries of the Organisation for Economic Cooperation and Development (OECD) (del Río González, 2005).

Slow adoption and diffusion rates pose a problem, due to the time imperatives inherent with climate change and associated policy goals. As such, increasing our understanding of specific barriers to adoption is required. This understanding will aid the design and implementation of interventions that can overcome barriers. Subsequently, a key issue requiring attention at the policy, research and practice levels, is the successful adoption and diffusion of CSA technological innovations.

Several studies have considered the adoption of proenvironmental innovations within agriculture in developed country settings, such as in the wine and sheep industries in the USA and Australia (Cullen et al., 2013; Sneddon et al., 2011; Tey and Brindal, 2012). However, these examples lack the contextual specificities of Europe, such as the impact of the European CAP and typical production systems, and the drive by EU policy makers to establish CSA adoption as a strategic priority. Though the field of pro-environmental innovation adoption in general is well formed, there is a lack of previous research concerning hampering factors related to technological innovation in agriculture in EU settings, and to a greater extent specifically in terms of CSA. Indeed, much previous research on CSA within developed country contexts has focused on technical and policy areas, whereas this paper considers more socio-economic factors in relation to CSA technological innovation adoption. Further, this area of pro-environmental innovation illustrates an imbalance, where a transition towards CSA provides societal benefits, but delivers limited short-term benefits to the actors that must enact the changes, namely farmers. As such, understanding barriers in this context could highlight solutions that are applicable to other examples that also involve these imbalances.

This paper seeks to identify barriers that prevent the successful adoption of CSA technological innovations in the European Union. To achieve this objective, the paper takes an explorative approach using qualitative data collected from key informants in France, the Netherlands, Italy and Switzerland. In order to achieve this aim, a review of the relevant literature will be performed, before outlining a conceptual framework that will be used to explore the data that was collected through the interviews; following the presentation of the results, a discussion and conclusion are provided.

\section{Literature review and conceptual framework}

CSA can involve the implementation of a wide array of technologies, practices or actions, including for example water management, intercropping, agroforestry, integrated crop-livestock management approaches or the integration of renewable energy systems (Taneja et al., 2014). Although CSA includes a multiplicity of technological, policy and institutional approaches, the focus of this research concerns CSA technological innovations. In this paper we define these as hardware, software and org-ware that help solve climate induced problems in agriculture, including increased agricultural productivity, reduced vulnerability of agro-food systems to climate impacts and the reduction of GHG emissions (or enhanced GHG emission storage) (McCarthy, 2001). 


\begin{tabular}{|c|c|}
\hline Climate variability risks & $\begin{array}{l}\text { Multiple-constraint } \\
\text { mitigation }\end{array}$ \\
\hline $\begin{array}{l}\text { •information systems } \\
\text { (local data-agronomic } \\
\text { models) } \\
\text { - insurance options } \\
\text { •alert systems for } \\
\text { extreme events } \\
\text { •preventive } \\
\text { infrastructure } \\
\text { •new varieties and } \\
\text { protection practices } \\
\text {-institutional changes } \\
\text { i.e. revision of } \\
\text { 'Appellation d'Origine } \\
\text { Protégée' (AOP) rules; } \\
\text { regulations in food } \\
\text { markets }\end{array}$ & $\begin{array}{l}\text { - Life-cycle assessment } \\
\text { (LCA) } \\
\text { - logistic optimisation } \\
\text {-information and } \\
\text { control systems (e.g. } \\
\text { for inputs and manure } \\
\text { handling) }\end{array}$ \\
\hline
\end{tabular}

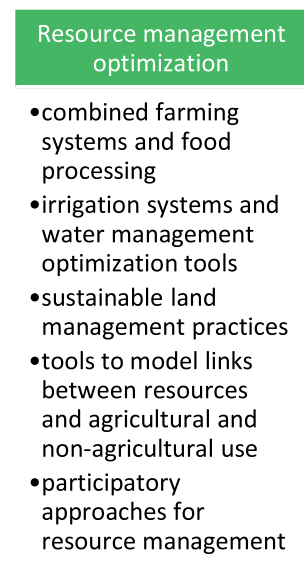

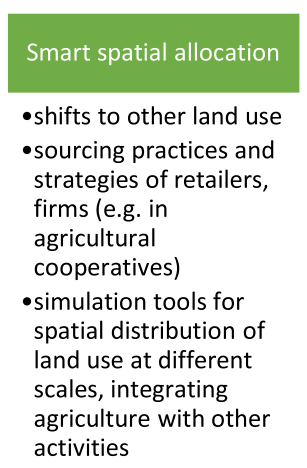

- shifts to other land use

-sourcing practices and tegies of retailers, firms (e.g. in agricultural cooperatives) spatial distribution of land use at differen agriculture with other activities

Fig. 1. Technological innovations relevant to CSA categorised according to climate change objective (CSA Booster, 2014).

CSA technological innovations at the field and farm level are those that have the potential to achieve the potential 'triple-win' associated with CSA, i.e. enhance the productivity of agricultural land, whilst simultaneously reducing climate change risks through mitigating GHG emissions or adapting the agricultural system (FAO, 2010; Scherr et al., 2012). Fig. 1 illustrates the type of technologies relevant to CSA, categorised according to specific climate change objectives. The concept of eco-innovation offers some value to the analysis of CSA technological innovations, as it is concerned with the process of developing new products, processes or services that provide added economic value, whilst also substantially reducing environmental impacts (Horbach et al., 2012); this relates well to CSA, which similarly seeks to increase productivity or incomes/ economic outcomes, as well as mitigation or adaptation benefits. It is recognised that adoption of an innovation alone may not achieve optimal outcomes, due to mismatches between the technological innovation design and the context within which it is ultimately used; as such, adoption of technology can be seen as a process of adaptation and appropriation. Suboptimal outcomes can occur due to a lack of user participation in the design process (Wever et al., 2008), and due to top-down, rather than bottom-up design methods. To ensure appropriate use of technologies, the concepts of 'user-centred innovation' or 'co-creation' are proposed, as this form of design can increase the positive impact of pro-environmental innovations (Wever et al., 2008). So, whilst on the one hand ecoinnovation is comparable to CSA, eco-innovation opens a specific perspective on CSA innovations that enables the consideration of the innovation process as a process of adaptation and appropriation.

Additional important considerations for understanding the characteristics of barriers to technological innovation adoption include their internal (i.e. behaviour or senior management) versus external (i.e. government policy) operation (Boons et al., 2013; Brunke et al., 2014). These approaches to categorising and understanding barriers are able to include all decision-making actors within our analysis of the barriers, and can also illustrate the interlinkages. However, to further strengthen this approach to categorising and understanding how barriers operate, the method employed by Wheeler (2008) can be included, which categorises barriers according to their location on the supply or demand side of the adoption and diffusion process. Fig. 2 demonstrates our initial framework for CSA technological innovation diffusion; this was constructed following the review of the literature and illustrates the authors' conceptualisation of the phenomena in hand. Through the literature review different levels at which barriers can operate are identified, via a demand or supply side, and in terms of their internal or external operation.

\subsection{Innovation studies}

The study of innovation has a long past with a historical split between research that sought to understand patterns of diffusion (often through the use of methods such as logistic modelling), versus attempts to understand the structure and process of decision-making that influenced the adoption of innovations (Montalvo, 2008). Rogers (1962), an early contributor to the study of innovation diffusion and adoption, highlighted 5 factors that impact the extent to which an innovation will spread and be used. These included the relative advantage of the innovation, compared to the previous generation of products; the innovations comparability to existing products, effecting how easy it is to adopt; it's complexity or simplicity, including perceptions of this; its trialability or testability, in terms of the opportunity to experiment with the innovation; and finally, observability, in terms of how easy it is for others to observe its use and effects.

The innovation studies literature examines the diffusion and adoption of a range of innovations, including technological innovation, but has also covered topics such as business model innovation or the use of e-markets (Ceschin, 2013; Johnson, 2010). Much recent literature has focused on pro-environmental and sustainable technological innovations, covering topics such as the installation and diffusion of smart-grid technologies (Luthra et al., 2014), energy efficiency retro-fitting innovations in the building sector (Faber and Hoppe, 2013; Hoffman and Henn, 2008) and in industry and manufacturing (Brunke et al., 2014; del Río González, 2005). Technological innovation within agricultural settings, in both developed and developing country contexts, is also evident (Cullen et al., 2013; Eidt et al., 2012; Huang et al., 2013; Luken and Van Rompaey, 2008; Wheeler, 2008).

Although literature is available concerning the factors that affect the adoption of innovative practices and technologies in agriculture in developing countries (Cullen et al., 2013; Eidt et al., 2012; Huang et al., 2013; Luken and Van Rompaey, 2008; Wheeler, 2008), these are often set within the context of small-holders and a low initial level of technological or practical sophistication. As such, the literature concerning innovation within the more technologically advanced or developed world will be the focus of the remainder of this section. Further, whilst it is highlighted that the factors and barriers experienced in terms of pro-environmental innovations are very similar to that of 'normal' technological innovations (Kemp 


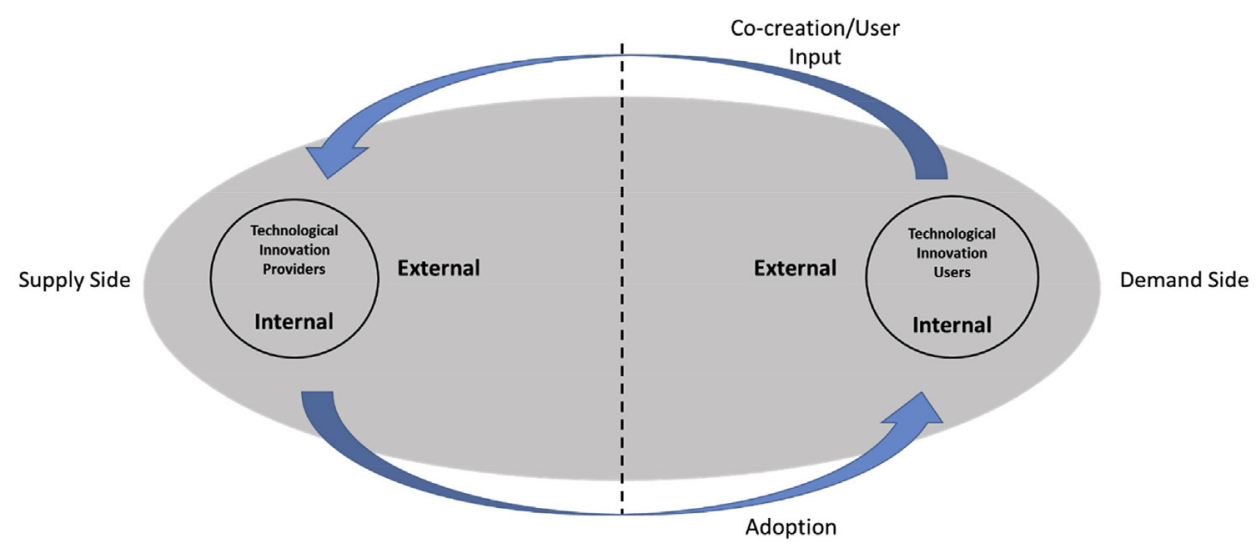

Fig. 2. Barriers to technological innovation adoption theoretical framework.

and Volpi, 2008), it is likely that some social, behavioural and economic aspects may differ due to the unique context of climate change and agriculture.

\subsection{General barriers to the adoption of technological innovations}

Based on the literature, several types of barriers are mentioned to be relevant in the adoption and diffusion of technological innovations.

A key barrier well represented within the literature is the role of financial or cost factors. Simply, the cost of many technological innovations is prohibitive, especially early on in the diffusion process due to difficulties in initial commercialisation efforts. The expense of establishing production facilities, as technology developers transform themselves into technology producers, often means that profits are hard to obtain and increase the costs of the innovative product or service (Cullen et al., 2013; Faber and Hoppe, 2013; Luthra et al., 2014); these can be expressed as 'early adopter costs' (del Río González, 2005), and impact both technology users as well as technology producers. Relevant factors that impact the actual and relative costs of innovations include changes to input prices (Kemp and Volpi, 2008), if perverse subsidies exist for current technologies (Weiss and Bonvillian, 2013) or the willingness of customers to pay price premiums for products or processes with a lower environmental impact (Reinstaller, 2008). Whether the adopter or wider industry has the necessary skills and capabilities to integrate and use the innovation or where the current technological stock has a long capital life (damaging the relative economic benefits of new investments in new innovations), also effect the relative cost of innovations (del Río González, 2005; Montalvo, 2008).

Even where economic and technological barriers are low or have been overcome, the literature highlights a range of socio-economic, institutional and behavioural/psychological barriers at play (Hoffman and Henn, 2008). Innovation must be accepted to be adopted (Wheeler, 2008), which is affected by factors such as age or educational level of the adopter (Tey and Brindal, 2012); however, there is conflicting research over the specific impacts of age and experience on willingness to adopt innovations. Drawing on psychological and sociological perspectives in their study of the adoption of green building practices, Hoffman and Henn (2008) found that individuals seemingly acted irrationally, over discounting the future, suffering from overly positive illusions (seeing the future as better than it is likely to be) (Vishwanath, 2009) and enacting presumed associations (such as green practises associated with 'hippy culture') (Ratten and Ratten, 2007) to the detriment of sustainable outcomes. Organisational impacts are also noted, operating through the control of language and terminology, perverse rewards (often short-term), habitual routines and organisational inertia (Faber and Hoppe, 2013), leadership (Blok et al., 2014) and the CSR identity of the firm (Roelofsen et al., 2015).

Other key factors advanced in the literature include the impact of uncertainty and risk perceptions (del Río González, 2005; Johnson, 2010), market failures (such as information asymmetries) (Weber and Rohracher, 2012), and internal and external stakeholder pressures (Montalvo, 2008). Principle-agent issues such as landowners refusing efficient technologies for tenant farmers can also be identified, (Guerin, 2001) as well as cultural barriers (linked to consumer habits and expectations) (Ceschin, 2013) and the credibility and authority of advisers or consultants (Guerin, 2001; Johnson, 2010).

\subsection{Barriers to technological innovation providers}

Many of the barriers noted above are specific to the adopters of technological innovations. However it can be conceived that the sources of the barriers noted above lies with producers; this is one reason for splitting barriers into supply (technology provider) and demand (technology user) categories. That said, technological innovation producers suffer specific barriers as well. These can include financial barriers, such as inadequate funding, as well as the impact of risk avoidance behaviours (Andrews, 2006).

Innovating for sustainability, an area with clear links to the development of CSA technological innovation, is also highlighted as involving several barriers. These can include the impact of secondary stakeholders, where the innovations have wider societal impacts, such as the use of genetic modification in the development of new crop strains (Hall and Vredenburg, 2003). Further, the development of radical technological innovations requires the departure from existing knowledge bases, and can require novel administrative, organisational and infrastructure capabilities, all of which can present difficulties to firms managing and attempting to commercialise innovations (Bessant et al., 2014). These barriers provide a good illustration that many of the barriers involved impact on, or are caused by internal processes within the innovating firms.

Market forces can also be identified as a key barrier for technological innovation providers, for example where a technological 
innovation is having to compete against established products (Costa-Campi et al., 2014). In addition, current policy or administrative systems may not be supportive of technological innovations, especially where they represent a radical innovation (Weiss and Bonvillian, 2013); in such cases, accreditation may be effected or subsidies available for existing competing technologies may not be available for the technological innovations.

\subsection{Agriculture specific technological innovation adoption barriers}

A limited amount of research is available on the adoption of technologies and innovations within agricultural contexts in developed countries. These have covered the adoption of organic or genetic engineering practices within Australian agriculture (Wheeler, 2008), precision agricultural technologies (PATS) (Tey and Brindal, 2012), vineyards in New Zealand (Cullen et al., 2013) and Australian wool farmers (Sneddon et al., 2011). These studies demonstrate that whilst there is overall little difference between more general technological innovation adoption, some context specific factors do exist, such as the specifics of industry types or differing national regulatory environments.

For instance, many of these studies highlight the seemingly irrational and inefficient outcomes of technological innovation adoption in these contexts. This includes the citing of examples of effective successfully adopted technologies and innovations being rejected by users, who revert back to the original practice or technology even where benefits were being enjoyed (Bewsell and Kaine, 2005; Cullen et al., 2013; Sneddon et al., 2011; Wheeler,
2008). These are explained through the role of communication channels and social networks and the primacy of perception, in terms of the perceived (rather than actual) benefits of adoption. The interaction of sources of information and how they influence perception (including imitation within adopter groups) is seen as key, including the role of powerful external influences such as technological advisers or advocates (Sneddon et al., 2011; Wheeler, 2008). The core barrier which is identified by these studies is the financial cost of the technology or innovation to the adopter; in other words 'the commercial and practical realities'. Conflicts between new technological innovations and traditional methods, the use of overly scientific language or jargon and a lack of appreciation of the 'day-to-day' reality on a farm by researchers and the producers of technological innovations, is also highlighted (Eidt et al., 2012).

The outcome of the interplay of these factors is lamentable, due to the often high social benefits of pro-environmental technologies and innovations within agriculture. These can include the buying of inputs locally, benefiting local communities, which are often not included within the adoption calculations of farmers and other agricultural producers. Due to this, and the often narrow economic benefits, targeted policies are advocated, in terms of focusing policies specifically onto the issue at hand. In this example, rewarding farmers directly for buying inputs locally (Cullen et al., 2013).

In order to provide an overview, the key barriers to the adoption of pro-environmental technological innovations, both general and specific to agriculture, is provided in Table 1.

Table 1

Overview of barriers to the adoption of pro-environmental technological innovations (general and agriculture specific) based on literature review.

\begin{tabular}{|c|c|c|}
\hline Barrier & & Sources \\
\hline Economic & $\begin{array}{l}\text { High initial investments } \\
\text { Poor access to capital } \\
\text { Hidden costs } \\
\text { Competing financial priorities } \\
\text { Long pay-back periods (ROI) } \\
\text { Switching costs/existence of installed base } \\
\text { High implementation costs (actual and perceived) } \\
\text { Uncertain returns and results } \\
\text { Temporal asymmetry between costs and benefits } \\
\text { Over discounting the future }\end{array}$ & $\begin{array}{l}\text { (Bogdanski, 2012; Brunke et al., 2014; Cullen et al., 2013; } \\
\text { del Río González, 2005; Faber and Hoppe, 2013; Hoffman } \\
\text { and Henn, 2008; Luken and Van Rompaey, 2008; Luthra } \\
\text { et al., 2014; McCarthy et al., 2011; Montalvo, 2008) }\end{array}$ \\
\hline Institutional/regulatory & $\begin{array}{l}\text { Low institutional support } \\
\text { Use of overly scientific language (Jargon) } \\
\text { Farmer's knowledge not considered in R\&D } \\
\text { Lack of regulatory framework } \\
\text { Prohibitively prescriptive standards }\end{array}$ & $\begin{array}{l}\text { (Bogdanski, 2012; Eidt et al., 2012; Luthra et al., 2014; } \\
\text { Montalvo, 2008) }\end{array}$ \\
\hline Behavioural/Psychological & $\begin{array}{l}\text { Lack of management support/awareness } \\
\text { Conflict with traditional methods } \\
\text { Overly complex technologies } \\
\text { Results/effects of technology difficult to observe } \\
\text { Farmer's beliefs and opinions } \\
\text { Low trust of advisers or consultants/lack of acceptance } \\
\text { Irrational behaviour } \\
\text { Negative presumed assumptions }\end{array}$ & $\begin{array}{l}\text { (Brunke et al., 2014; Eidt et al., 2012; Hoffman and Henn, } \\
\text { 2008; Johnson, 2010; Ratten and Ratten, 2007; Sneddon } \\
\text { et al., 2011; Vishwanath, 2009; Wheeler, 2008) }\end{array}$ \\
\hline Organisational & $\begin{array}{l}\text { Lack required competencies/skills } \\
\text { Poor readiness } \\
\text { Poor information } \\
\text { Inability to assess technologies } \\
\text { Overly short-term/perverse rewards } \\
\text { Organisational inertia/habitual routines }\end{array}$ & $\begin{array}{l}\text { (Brunke et al., 2014; Faber and Hoppe, 2013; Johnson, 2010; } \\
\text { Luken and Van Rompaey, 2008; Luthra et al., 2014; } \\
\text { Montalvo, 2008) }\end{array}$ \\
\hline Consumers/Market & $\begin{array}{l}\text { Poor information } \\
\text { Lack market attractiveness/do not align to preferences } \\
\text { Uncertainty } \\
\text { Consumers/farmers level of motivation } \\
\text { Market uncertainty }\end{array}$ & $\begin{array}{l}\text { (Bogdanski, 2012; Bohnsack et al., 2014; Brunke et al., 2014; } \\
\text { del Río González, 2005; Johnson, 2010; Luthra et al., 2014) }\end{array}$ \\
\hline Social & Social/peer pressures & (Montalvo, 2008) \\
\hline
\end{tabular}


Table 2

Technology provider data sources/participants \& description of technological innovations.

\begin{tabular}{|c|c|}
\hline No. & Technological innovation description \\
\hline P1 & $\begin{array}{l}\text { Provides software and new tools, managed } \\
\text { through the internet, in order to optimise yields } \\
\text { and quality of grapes in vineyards. Can integrate } \\
\text { sap flow sensors, drones etc. Allows precise } \\
\text { irrigation and detailed view of vineyard } \\
\text { operations, according to wine quality goals. }\end{array}$ \\
\hline
\end{tabular}

P2 The technology combines two competencies: remote sensing and agronomic models to develop precision farming. Integration of satellite data in agronomic models.

P3 New assessment, certification service and related tool for communicating sustainability performance, according to various standards. This approach can assist and improve the sustainability of products and processes through life-cycle assessment, and enhance marketability.

P4 Biogas plants trading within the Swiss GHG emissions scheme and improving the quality of fertilizer. Allows farmers to send waste to biogas plants, and at no cost, is returned as an improved fertiliser.

P5 Feed additive that can reduce GHG emissions from ruminants, as well as increasing farm yields.

P6 LED horticulture/urban farming.

P7 Use water treatment plant by-products to produce fertiliser and pig feed additives.

P8 Standalone water salinity regulator. This decreases the salinity of surface and ground water, preventing negative impacts and optimizing salinity levels to the crop development stage.

P9 Remote sensing technologies for assessing water quality. The portable system reduces the time required to take measurement, and provides greater in-situ accuracy. Potential users include researchers, water managers and most significantly in aquaculture; here it can help with the prediction of algal blooms or optimum harvest times.

P10 Precision automated irrigation systems that integrates meteorological data. Decreases water and energy use/increases productivity.
Food

processors.

On-farm.

On-farm.

On-farm.

Product on the market.

\begin{tabular}{|c|c|c|}
\hline $\begin{array}{l}\text { Chain stage of } \\
\text { use }\end{array}$ & Development stage & Potential CSA impact \\
\hline On-farm. & $\begin{array}{l}\text { Product on the } \\
\text { market. }\end{array}$ & $\begin{array}{l}\text { Productivity/Incomes: allows improved grape/ } \\
\text { win quality. Reduces crop variability due to } \\
\text { weather fluctuations. } \\
\text { Adaptation: provides greater understanding of } \\
\text { how crop responds to weather and improves } \\
\text { management ability. } \\
\text { Mitigation: improves resource use, including } \\
\text { irrigation, increasing efficiency, lowering GHG } \\
\text { emissions. }\end{array}$ \\
\hline
\end{tabular}

Product on the market.

On-farm. Product on the market.

On-farm. Field trials and initial market exploration.

On-farm. Product on the market.

Field trials and initial market exploration.

Adaptation: Reduces water usage, improving
Productivity/Incomes: improves time

management due to greater understanding and information.

Adaptation: improved understanding through technology potentially allows better decisionmaking under weather uncertainties.

Mitigation: saves inputs, potentially reduces

GHG emissions.

Productivity/Incomes: improves communication

of pro-environmental products, increasing marketability. Also allows identification of

'hotspots', enabling focused actions.

Adaptation: 'Hotspot' analysis could aid in

highlighting vulnerabilities in the supply chain.

Mitigation: 'Hotspot' analysis could aid in

highlighting vulnerabilities in the supply chain.

Productivity/Incomes: provide improved

fertiliser to farms, based on their own waste.

Adaptation: no impact.

Mitigation: reduces GHG emissions through the

generation of renewable energy.

Productivity/Incomes: can increase yields.

Adaptation: no impact.

Mitigation: reduces GHG emission from

ruminants.

Productivity/Incomes: Reduced heat load

compared to conventional lighting, allowing

improved light distribution, with associated

positive growing impacts.

Adaptation: (indirect) increases viability of

horticulture, which is less vulnerable to

weather variations.

Mitigation: $1 / 3$ rd more efficient than

conventional approaches, reducing energy use and hence GHG emissions.

Productivity/Incomes: valorisation of previous

waste stream with some economic benefits to

users (farmers), i.e. lower phosphate levels and reduces run-off issues. As feed additive, it is 'organic' compatible.

Adaptation: no impact.

Mitigation: replaces high GHG emission

fertilisers, resulting in GHG emission

reductions.

Productivity/Incomes: can reduce costs

associated with water supply infrastructure and

saline levels.

Adaptation: mitigates against saline ingress due to the rising sea-levels.

Mitigation: Energy neutral.

Productivity/Incomes: For aquaculture, increases accuracy and reduces time needed to take measurements, increasing efficiency. Also reduce risks of algal blooms, and optimises harvest timing.

Adaptation: improves algal bloom forecasting. Mitigation: little impact.

Country

France

France

Italy

Switzerland

Switzerland

The Netherlands

The Netherlands

The Netherlands

Productivity/Incomes: reduces water usage and increasing productivity of the crops.

water stress risks locally. Also uses

meteorological data, and so is able to respond to weather variability.

Mitigation: reduction in water use may result in reduced GHG emissions. 


\section{Methods: data collection and data analysis}

\subsection{Data collection}

Data for the study was collected during a European project funded by Climate KIC, called the CSA Booster. This project sought to explore barriers and bottlenecks to CSA technological innovation adoption and diffusion, and to identify services which could enhance and secure the adoption of CSA technologies in the European agricultural sector. This project was undertaken with partners in the Netherlands, France, Italy and Switzerland.

As limited information was available on barriers to CSA technological innovation adoption and diffusion within the European context, this research took an exploratory approach. As such, the theoretical framework constructed at the start of section two will be used to guide the study, but the research will seek to identify previously undocumented factors and barriers that are potentially unique to CSA technological innovations as well. Following from this exploratory approach, this research took a qualitative stance, and therefore sought to identify key themes relevant to the research questions. In order to gather rich and in-depth data on the barriers, the qualitative analysis of semi-structured interviews with key informants was chosen as the research method.

26 Interviews were conducted with CSA technology providers and potential end-users/customers; end-users included farmers associations and consumer goods producers and retails, to provide a range of perspectives from within agro-food supply chains. In addition, data was also obtained from financial actors. Participants were selected using a non-probabilistic purposive sampling strategy, as suitable examples were limited (Bogner et al., 2009). This was due to the need to obtain information from businesses with technological innovations relevant to CSA and potential users with a demand for CSA technological innovations. Participants were primarily identified through internet searches and co-nomination, and then approached for interviews.

Tables 2 and 3 provide an overview of the participants interviewed during the research; in addition, Table 2 provides a description of each technology, including where in the agro-food chain it is used, its CSA impacts and its development stage. The data provided through these interviews was able to shed light on the key barriers operating within this context. These interviews took a semi-structured format with the interview questions identified and formed through reviews of the literature and consideration of the research questions. The questions were designed to be neutral and non-leading. The interviews were conducted by project partners, using a standardised questionnaire protocol and recorded into a standardised template in order to allow comparability of the data.

\subsection{Data analysis}

Once the data was collected, analysis took place through the coding of typical and frequently mentioned elements, as well as information critical to the answering of the research questions. Thematic analysis formed the focus of the analysis efforts; once the coding was completed it was checked by all members of the research team for consistency and strength. The categorisation of the data, via Atlas.ti, involved numerous iterations to maximise internal consistency within the categories. Once complete, this process produced a range of codes and categories, with a variety of layers, identifying key themes.

For example, P6 represented a firm that had developed an LED farming technological innovation for use in horticulture or 'urban farming'. Through the interview, the respondent noted that their product effectively replaced the existing lighting used by horticulture, with a more efficient system, that allowed more even coverage. The innovation reduced energy consumption and costs, as well as being applicable to new settings, such as urban farming; within certain locations, the product was doing well, but in other regions less so. However, they reported problems convincing farmers of the product, partly due to a complicated installation/roll-out phase with the product. They also lacked information on additional or new market opportunities, including access to local networks. Finally, the business felt that they lacked a deep enough understanding of customer wants and needs in the industry, as they had developed a comprehensive product, with financing available, but were experiencing limited demand.

Initial coding in Atlas.ti sought to identify problems or barriers expressed by the respondents; as such, all the elements described above were initially flagged as problems or barriers. The next stage involved categorising barriers by seeking commonalities or generalisations between different respondents. In the case above, their first issue (convincing farmers) was assigned to the category 'Difficulty in proving value and demonstrating impact' and the second problems, with regard to lack of knowledge of markets and access to local networks was assigned to access to, and reaching customers'.

The reported barriers are split according to their location on the supply or demand side of the adoption process. Supply side barriers were those that were experienced by technological providers, whilst demand side barriers were those reported by potential users of the technological innovations. It should be noted that all barriers identified and presented are not ranked or ordered in terms of importance; this is due to the exploratory nature of the research, and the desire to simply identify key factors as a first step in this emerging field of research.

\section{Empirical findings}

\subsection{Barriers hampering technology providers}

Technology providers reported a range of barriers that inhibited their ability to sell and distribute their technological innovations, which results in reduced levels of adoption and diffusion. These are summarised in Table 4, before being described in more detail.

a. Proving value of the product/demonstrating impact: technology providers reported that they are hindered in the selling of their technological innovations due to difficulties in proving the value of their technological innovations. It was also reported that it is difficult to establish that the innovations work as claimed. Scientific or impact studies are often required to prove impact and highlight value, however, these were highlighted as often being complex and expensive.

[The] main problem was convincing potential customers that it works, since it's a new technology. (P7)

Convincing customers is a hard one. We do have small scale pilot and demonstration projects at farmers' places but [it is] still hard to convince the actual customers of buying the product. The risk for the farmer is high if it doesn't work. It depends on the local circumstances, but mostly the out-roll phase is the complicated one, it goes slowly. (P6)

It's difficult to demonstrate in the short term the positive gain of the technology because grape production is separated from wine production. It's not always easy to assess the impacts. (P1) 
Table 3

Technology user data sources/participants.

\begin{tabular}{|c|c|c|}
\hline No. & Description & Interview country \\
\hline U1 & Financial services, with interests in agro-food chains & The Netherlands \\
\hline $\mathrm{U} 2$ & Dairy products company & The Netherlands \\
\hline U3 & European-level farmers association \& trade body for agro-cooperatives & The Netherlands \\
\hline $\mathrm{U} 4$ & Farmers association & The Netherlands \\
\hline U5 & Sugar processor & The Netherlands \\
\hline U6 & Consumer goods producer & The Netherlands \\
\hline U7 & Agro-chain investor & France \\
\hline U8 & Vendor for livestock feed products & France \\
\hline U9 & Financial and industrial actor of French oleaginous and protein seeds industry & France \\
\hline U10 & Potato farmers association & Italy \\
\hline U11 & Farmers association & Italy \\
\hline $\mathrm{U} 12$ & Support organisation for clean/pro-environmental farming techniques & Switzerland \\
\hline U13 & National retailer & Switzerland \\
\hline U14 & Global 'snacks' producer & Switzerland \\
\hline U15 & Supermarket & Switzerland \\
\hline U16 & Chocolate producer & Switzerland \\
\hline
\end{tabular}

Table 4

Barriers experienced by technology providers.

\begin{tabular}{ll}
\hline & Technology provider barriers \\
\hline a. & Difficulty in proving value and demonstrating impact \\
b. & Lack of knowledge of, and access to capital/investment \\
c. & Unsympathetically regulatory landscape \\
d. & Product is too expensive/ROI periods too long for customers \\
e. & Access to, and reaching customers \\
\hline
\end{tabular}

b. Lack of knowledge of, and access to capital/investment: Technology providers noted a lack of knowledge of, and access to capital and investment, meaning that expansion and other business objectives requiring financing were unable to be pursued; for instance, linked to the above noted barriers, without access to this finance, impact studies could not be conducted to prove the claimed impact of technologies. In some instances, technology providers pursued novel finance raising strategies, yet these were also hindered by lack of guarantees and other factors associated with start-up companies.

We don't ask for investors. The growth has been founded by clients, but we faced barriers; we are an innovative firm, not mature, so we can't give guaranties for investors. But at this step we want to control the development of our own technology ... (P1)

c. Unsympathetic regulatory landscape: Several technology providers highlighted issues with the policy and regulatory landscape, which acted as barriers to their ability to successfully diffuse their technological innovations. Included within this theme were factors such as inconsistent policies between different countries or regions, the lack of consistent carbon pricing (preventing the costing of GHG emission reductions), or having to compete against other products that qualified for, or had obtained subsidies.

On the policy side it is also very interesting. It is hard to get water boards and the ministry along, perhaps also because of the rigid agricultural policy sector in general. Contacts with customers (i.e. farmers) are generally good but the policy environment is not made for these kinds of technologies. (P8)

The regulations for electricity production feed-in tariff system in Switzerland does not support the technology (no farmyard manure is supported). (P4)

d. Products too expensive/ROI periods overly long: Technology providers highlighted that often they found that potential customers felt that their technologies were too expensive and/ or had ROI periods that were too long.

Payback time (ROI) for customers is about 4 years. (P8)

Currently we are charging 20000 euros for a device but we want to bring this down to 6000 euros since it clearly was too expensive. (P9)

e. Access to, and reaching customers: Many of the technology provider's interviews highlighted difficulties in identifying and reaching potential customers. This included identifying specific customers segments or where identified, finding successful avenues to contact and sell through.

Clearly, reaching the customer is the biggest issue at the moment. (P10)

\subsection{Barriers hampering technology users}

Demand side barriers were those that were identified through the responses of potential users of CSA technological innovations. These barriers impacted potential users and prevented or inhibited them from adopting CSA technological innovations. A summary is presented in Table 5 .

a. Low awareness of CSA/inaccessible language: CSA was reported to be a little-known phrase among potential users of CSA technological innovations. More widely, climate change and sustainability initiatives (including CSA) were associated with 'jargon', which non-experts found hard to understand and offputting. Potential users highlighted difficulties in accepting the need for CSA technological innovations due to the lack of a focus on 'business impacts'; for example, how technological innovations would impact 'efficiency', or if they were 'costeffective'. In addition it was noted that many potential users at the farm level only spoke their mother tongue, which meant that technology providers from different parts of Europe may find it difficult to access and communicate with farm-level users outside their native countries.

Extreme weather circumstances are becoming serious issues. So yes, it has an impact but don't call it 'climate'. It's more a language and communication issue. Talk to farmers about how the growing season is this year, don't talk about climate change. It's all in the language. (U4) 
Table 5

Barriers of CSA technology adoption as experienced by Technology Users.

\begin{tabular}{ll}
\hline & Technology user barriers \\
\hline a. & Low awareness of CSA and inaccessible language \\
b. & High costs and long ROI periods \\
c. & Lack of verified impact of technologies \\
d. & Regulatory and policy issues \\
e. & Hard to reach and train farmers \\
f. & R\&D and policies not match to 'on-the-ground' reality \\
g. & Low consumer demand \\
h. & Unequal distribution of costs/benefits across supply chains
\end{tabular}

b. High costs and long ROI periods: Simply, many potential users of CSA technological innovations noted that they were too expensive; this manifested itself in terms of high upfront costs and/or overly long ROI periods.

Often costs. For instance with the drip [irrigation] system: if you have a lot of acres, you will need a lot of rubber. Cost can be an issue then. [It is] only beneficial if you have the right conditions. In the end it is a cost benefit analysis. (U4)

Major difficulties are due to the cost of investment, which is not enough balanced by the increase of yield nor the price of agricultural products. (U11)

Many technologies have long payoff times and do not fulfil internal payoff criteria. However payoff criteria would be fulfilled with clear carbon price. (U13)

Cost of investment is quite high because farmers in Switzerland suffer from enormous cost pressure compared to other markets, cost of labour and inputs are anyway high in Switzerland. Cost of investments are also high because in Switzerland, we have a lot of small-medium sized farms, which mostly don't have large financial investment possibilities. (U12)

c. Lack of verified impact of technologies: In order to invest in technologies, potential users noted that they needed assurances over the impacts of technologies. These are often lacking with CSA technologies, which as new products, do not have a track record, and regularly lack supporting impact studies.

Technologies should have a proven impact, so farmers are convinced to use it. (U2)

Unclear climate impact of specific agricultural technologies (compared to e.g. fuel switch in transportation). Quantitative information on impact is necessary to evaluate technologies. Internally, we need to know quantitative impacts; often more research is required. (U13)

d. Regulatory and policy issues: Policy and regulatory barriers related to issues such as some countries placing greater emphasis on climate mitigation over adaption, or for example the lack of a clear carbon price. Inconsistencies between national and EU level policies were also highlighted.

Also, the implementation of unequal rules among the regions (policies and regulations), more strict rules related [to] environmental protection makes farmers less competitive, as consumers are not well informed on efforts made by companies who wants to take care of the environment and climate adaptation. (U11)

In Switzerland we have a focus on energy efficiency and renewable energy in policy, so we realize projects mostly in these areas. (U12)

e. Hard to reach and train farmers: Some potential users of the CSA technological innovations (and technology providers) are based several supply chain stages away from the farm, meaning that no direct commercial relationship exists. This makes it hard to reach and impact farmers upstream in the supply chain. This barrier reflected difficulties experienced by food industry actors, rather than farmers; this was often the case where actors downstream in agro-food chains were engaging with suppliers and encouraging uptake of technological innovations. In addition, some farmers were reluctant to change tried and tested traditional farming methods.

We can't do it alone. We simply don't have the expertise so we have to work together with NGO's or others in order to ... . get access to farmers because we usually don't have that, we only talk to our suppliers not to the farmers. (U6)

Agriculture is a generational activity: it can be difficult to overcome old traditions, Training in using new technologies can therefore be difficult. (U14)

f. R\&D and policies do not match to 'on-the-ground' reality: It was highlighted by the respondents that policy and research is often made and conducted away from the farm, meaning that it neglects many 'day-to-day' realities faced by farmers. In turn, this means that technologies that are developed or subsidies do not match the demands or needs of farmers.

Also do your research together with farmers; only then will you be able to make an impact. (U4)

All supply chain parties play an important role. They have their own goals towards CSR. But the last step towards the farmer is the hardest, they are usually too far away to understand what is going on at the farm. Unilever can have beautiful CSR goals but having those goals for themselves doesn't really mean they enable farmers to do what's best. (U4)

g. Low consumer demand: Linked to the reported relatively high costs of CSA technological innovations, potential users noted that if they adopted the technological innovations, this would lead to price increases for the end products bought by consumers. The central hindrance noted by potential users was that consumers were unwilling to pay a price premium for CSA products. This lack of demand for products produced in line with CSA principles, meant investment in, and the adoption of CSA technological innovations made little 'business' sense.

We have no products labelled somehow climate friendly. We see no demand from consumers. (U2)

h. Unequal distribution of costs/benefits across supply chains: The unequal distribution of costs and benefits across agro-food supply chains was noted as reducing the motivation of farmers to adopt CSA technologies. Specifically, this is due to a mismatch where many of the economic benefits are located downstream, with consumer products companies or retailers, whilst many of the environmental/climate benefits are located on the farm.

CSA/sustainability is mostly more costs for farmers, so we want to farmers to keep the money/benefit. Mostly the economic benefit goes into the upstream supply chain; we mostly save money on input reduction (less energy used). (U2)

\subsection{Results overview}

The results are now able to be plotted on to the initial theoretical framework (Fig. 2) developed via the review of the literature. This highlights the key barriers experienced by technological innovation 
providers and users, separated according to the barriers position on the supply or demand side.

\section{Discussion}

The results obtained through the data analysis illustrate the barriers that are currently inhibiting the adoption and diffusion of CSA technological innovations in Europe. Data was collected from key respondents on both the demand and supply sides, including technology providers as well as potential users. By taking an exploratory and qualitative form, we are able to propose typologies of barriers for the adoption of diffusion of CSA technological innovations in Europe.

\subsection{Novelty of the barriers for CSA}

In terms of previously identified barriers to technological innovation adoption and diffusion in the literature, costs and other financial factors were well represented in our results (Cullen et al., 2013; Faber and Hoppe, 2013; Luthra et al., 2014). In our study, costs barriers were noted and recognised by both technology providers and potential users. As many of the technology providers included within the survey were attempting to sell young technologies still in development, these can be seen to be consistent with del Río González (2005) and their assertion regarding 'early adopter costs' for potential users of the technological innovations. Further, the lack of consumer demand identified by potential users is also highlighted in the wider literature, by Reinstaller (2008), and their assertion that consumers will not pay a premium for products with lower environmental impacts.

Other barriers present within the wider technological innovation adoption literature that are confirmed through this study include the impacts of language and terminology (Faber and Hoppe, 2013) and policy and regulatory issues, such as problems with accessing subsidies that are available for competing technologies (Weiss and Bonvillian, 2013). This highlights that some general barriers are also relevant to the specific case of CSA in Europe.

Previous literature also point towards the credibility and authority of advisors and consultants as impacting adoption and diffusion levels (Guerin, 2001; Johnson, 2010), and whilst this did not emerge as a key theme through the data coding, it could be seen to be consistent with issues related to overly complex language and 'jargon'. It was noted these were often used by experts in relation to CSA and more widely sustainability. Indeed, this has previously been noted specifically within agricultural contexts (Eidt et al., 2012), and relates to the lack of appreciation, in policy and research, of day-to-day farm realities, identified both in this study and in the literature (Eidt et al., 2012).

A lack of skills highlighted by del Río González (2005) and Montalvo (2008) were not identified explicitly by any of our respondents. However, as a lack of awareness of CSA and associated technological innovations was identified, a lack of skills may not yet have been recognised, due to the immature nature of the CSA technological innovation market. The impacts of age or educational level on adoption were also not identified explicitly within our results, although this was not a direct question asked through the interviews. However, potential users' further downstream agrofood supply chains, such as retailers, noted that it was difficult to reach and train farmers. The impact of mismatched costs and benefits across supply chains, resulting in farmers receiving few economic benefits, can be related to Cullen et al. (2013). They found that adoption decisions by farmers are shaped by narrow economic benefits, excluding possible social or environmental benefits.
In summary, whilst some of the barriers identified through this study are found within the literature, several aspects may be more novel to the context of CSA; specifically, these include the difficulties of technology providers in demonstrating and proving the value of their technological innovations, a lack of access to and knowledge of capital and finance (although this relates somewhat to cost barriers) and difficulties in accessing and reaching customers.

\subsection{Results through the conceptual framework}

The framework constructed following the literature review (see Fig. 2) worked well in allowing an exploration of key barriers to CSA technological innovations. Based on the results, more detail is able to be added to the theoretical framework (see Fig. 3). The separation of barriers onto supply and demand sides worked well in relation to the study design and was able to highlight where key barriers existed - in turn this is able to inform the formulation of policy recommendations and the design of propositions to alleviate the barriers. The separation of barriers on to supply and demand sides illustrates the nature of problems faced by different actors well, and aids the development of value propositions to overcome these barriers. The conceptual frameworks splitting of the barriers into internal and external aspects is less helpful, as many of the barriers identified through the analysis do not neatly fall into such a categorisation.

\subsection{Tackling the barriers: interventions from all sides}

What is clear from the results is that barriers are present on both the supply and demand sides. This means that any measures designed to enhance and boost the diffusion and adoption of CSA technological innovations will have to target both sides of the adoption and diffusion equation to be effective. Based on these results, a range of potential solutions can be postulated and issues that require further research to deepen our understanding can be identified.

First, the supply or producer side of the issue will be examined. The sources of many of the user or demand side barriers can be drawn back to a lack of appreciation of user needs and wants by those who design and provide technological innovations. These include the lack of consideration given to 'on-the-ground realities' in policy and R\&D or issues around jargon and overly scientific language. Further, it can be seen that difficulties exist in reaching and accessing customers and demonstrating the value and impact of CSA technological innovations, experienced by technology providers. These issues could at least be eased where greater engagement existed with potential users earlier in the innovation process. This assertion draws strong parallels with the concept of user centred innovation or co-creation (illustrated in Figs. 2 and 3), as these approaches explicitly try to overcome these barriers upfront by involving users in the design and development process (Lockton et al., 2008; Wever et al., 2008). In this sense, it is possible to assert that CSA technological innovations covered in this research have not integrated user-centred innovation principles. As such, user-centred design or co-creation could help overcome several of the barriers identified.

As the cost of technology adoption is relatively high while the ROI is relatively ( $\mathrm{s}$ )low, a better balance between costs and benefits of technology adoption throughout the supply chain is also identified as necessary. Because users towards the consumer end of agro-food chains are interested in sustainable sourcing strategies, they can be seen as an important driver for the adoption of CSA technologies upstream the supply chain. By instilling the principles of user-centred innovation, technology producers will be better 
Barrier

Characteristics

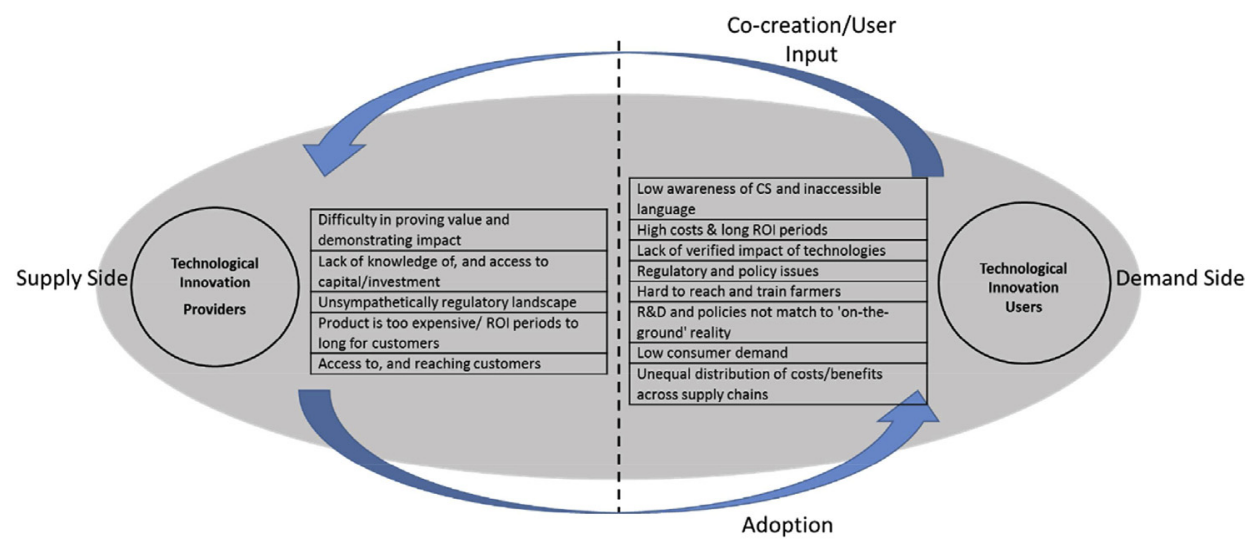

Fig. 3. CSA technological innovation barrier framework.

able to design technologies that benefit users at the top of agrosupply chains. Secondly, policymakers can be seen to have a key role to play. Policymakers aim to enable innovation, especially since the previous financial crisis. Whilst traditional 'supply side' measures, such as state support for start-up companies or tax-breaks for research and development efforts, could play a role $(\mathrm{OECD}$, 2014), measures aimed at the demand side will also be required (Edler, 2007). Tax-breaks may reduce the costs associated with CSA technological innovations, impacting the cost and ROI barriers identified on both the demand and supply sides. However, other barriers, such as lack of access to and knowledge of potential customers and the inaccessible language within which CSA (and wider sustainability) is framed, will be left unaffected.

As policy issues were identified as a barrier by both technology producers and potential users, policies at the regional, national and European level should also be examined. These policies need to be compatible with CSA objectives and their ability to boost the development and adoption of CSA technological innovations in Europe. More generally, to facilitate the selection and adoption of CSA technologies, awareness of CSA needs to be increased, as well as the collaboration between farmers, industry and technology providers (Wubben et al., 2012). Education programmes and awareness raising campaigns could be launched; these would better prepare technology providers to address the market needs of their customers, and end-users for the adoption of these technologies. This will also raise the profile of CSA in particular and the impact of climate change on agriculture more generally. Actions should also be considered in terms of promoting and facilitating 'user-centred' innovation and co-creation, by bringing together technology producers and the end-users (Blok et al., 2015).

Action should be taken that supports CSA technology providers in the development of business models for their CSA technology, identifying suitable customer segments and entering the market. In order to develop business models for particular CSA technologies, technology providers require other actions, including a CSA technology broker to identify new customer segments and new markets. In addition, aid with impact analysis of CSA technological innovations and potentially a labelling scheme would allow the economic and climate impacts of the technologies clearly demonstrated, providing evidence and reassurance to the eventual adopters and end-users.

It should be recognised that this research was exploratory in nature and based on a limited sample. As such the current analysis is able to identify key typologies of the barriers impacting the adoption and diffusion of CSA technological innovations. Further barriers may exist, which were not identified through this research. This may and should be seen as an initial step to gaining a more comprehensive understanding of the barriers preventing the enhanced adoption and diffusion of CSA technological innovation in the Netherlands, France, Italy and Switzerland. The identification of these typologies may aid data collection efforts for future research.

Future research should seek to validate our results through larger samples, including other European countries not included in this research. Further possibilities include taking a more quantitative approach, and seeking to establish which barriers are most pervasive, by ranking the barrier typologies identified with this research.

\section{Conclusions}

This research has sought to identify key barriers inhibiting the adoption of CSA technological innovations in the Netherlands, France, Italy and Switzerland. By undertaking an interview survey of both technological innovation producers and potential users, via semi-structured interviews, a range of barriers were identified, located on both the demand and supply sides.

By identifying barriers to CSA technological innovation adoption, this research has provided a first assessment of the context of CSA technological innovations in European countries. This is important, due to the imperative of agriculture undergoing a transition to adapt to the impacts of climate change and adjust to the demands associated with climate mitigation objectives. By undertaking this assessment, this research has illustrated the key barriers that need to be overcome in climate proofing European agriculture systems, according to our sample of potential users and technological innovation providers. In turn, this allowed a discussion of provisional activities and policy measures that may need to be enacted in order to enhance and boost technological innovation for CSA in the Netherlands, France, Italy and Switzerland; these results may also be relevant to other European countries, however further research will be required to for this to be confirmed. A key result of this research identified that barriers exist on both the demand and supply sides, indicating that traditional supply based innovation policies alone will be unlikely to lead to sufficient levels of technological innovation adoption to aid the agricultural sectors transition to the practice of CSA.

This research has also contributed by linking the existing literature on barriers to technological innovation adoption, both in terms of literature specific to agriculture in developed country 
contexts and more generally, to the concept of CSA. This allowed the generation of a conceptual framework (see Fig. 3) for barriers to CSA technological innovation adoption, which may aid future research efforts in this area, in which the model can be tested and applied in various subsectors and -markets. This research has also found that many barriers that are applicable to wider technological innovation adoption are also relevant to the study of CSA.

\section{Acknowledgements}

The authors are grateful for the financial support provided by Climate-KIC that enabled the research upon which this paper is based.

\section{References}

Andrews, P., 2006. Five Barriers to Innovation: Key Questions and Answers. Executive Technology Report. IBM, USA.

Arslan, A., McCarthy, N., Lipper, L., Asfaw, S., Cattaneo, A., 2013. Adoption and Intensity of Adoption of Conservation Farming Practices in Zambia ESA Working Paper Np. 13-01. Agricultural Development Economics Division, FAO Rome, Italy.

Bessant, J., Öberg, C., Trifilova, A., 2014. Framing problems in radical innovation. Ind. Mark. Manag. 43, 1284-1292.

Bewsell, D., Kaine, G., 2005. Adoption of environmental best practice amongst dairy farmers. In: 11th Annual Conference of the New Zealand Agricultural and Resource Economics Society Inc. Nelson.

Blok, V., Long, T.B., Gaziulusoy, A.İ., Ciliz, N., Lozano, R., Huisingh, D., Csutora, M., Boks, C., 2015. From best practices to bridges for a more sustainable future: advances and challenges in the transition to global sustainable production and consumption. J. Clean. Prod. http://dx.doi.org/10.1016/j.jclepro.2015.04.119 (special issue).

Blok, V., Wesselink, R., Studynka, O., Kemp, R., 2014. Encouraging sustainability in the workplace: a survey on the pro-environmental behaviour of university employees. J. Clean. Prod.

Bogdanski, A., 2012. Integrated food-energy systems for climate-smart agriculture. Agric. Food Secur. 1, 9.

Bogner, A., Littig, B., Menz, W., 2009. Interviewing Experts. Palgrave Macmillan, Hampshire, UK.

Bohnsack, R., Pinkse, J., Kolk, A., 2014. Business models for sustainable technologies: exploring business model evolution in the case of electric vehicles. Res. Policy 43, 284-300.

Boons, F., Montalvo, C., Quist, J., Wagner, M., 2013. Sustainable innovation, business models and economic performance: an overview. J. Clean. Prod. 45, 1-8.

Branca, G., Lipper, L., McCarthy, N., Jolejole, M., 2013. Food security, climate change, and sustainable land management. A review. Agron. Sustain. Dev. 33, 635-650.

Branca, G., McCarthy, N., Lipper, L., Jolejole, M.C., 2011. Climate Smart Agriculture: a Synthesis of Empirical Evidence of Food Security and Mitigation Benefits from Improved Cropland Management. FOA Working Paper. Food and Agriculture Organisation, Rome.

Brunke, J.-C., Johansson, M., Thollander, P., 2014. Empirical investigation of barriers and drivers to the adoption of energy conservation measures, energy management practices and energy services in the Swedish iron and steel industry. J. Clean. Prod.

Ceschin, F., 2013. Critical factors for implementing and diffusing sustainable product-Service systems: insights from innovation studies and companies' experiences. J. Clean. Prod. 45, 74-88.

Commission of the European Communities, 2009. White Paper: Adapting to Climate Change: towards a European Framework for Action Commission of the European Communities (Brussels).

Costa-Campi, M.T., Duch-Brown, N., García-Quevedo, J., 2014. R \& D drivers and obstacles to innovation in the energy industry. Energy Econ. 46, 20-30.

Coumou, D., Petoukhov, V., Rahmstorf, S., Petri, S., Schellnhuber, H.J., 2014. Quasiresonant circulation regimes and hemispheric synchronization of extreme weather in boreal summer. Proc. Natl. Acad. Sci. U.S.A.

CSA Booster, 2014. Pathfinder Report. Climate Smart Agriculture Booster (Wageningen)

Cullen, R., Forbes, S.L., Grout, R., 2013. Non-adoption of environmental innovations in wine growing. N.Z. J. Crop Hortic. Sci. 41, 41-48.

del Río González, P., 2005. Analysing the factors influencing clean technology adoption: a study of the Spanish pulp and paper industry. Bus. Strategy Environ. $14,20-37$.

Edler, J., 2007. Demand-based Innovation Policy Manchester Business School Working Paper, No. 529 (Manchester; UK).

Eidt, C., Hickey, G., Curtis, M., 2012. Knowledge integration and the adoption of new agricultural technologies: Kenyan perspectives. Food Sec. 4, 355-367.

EIT, 2014. Innovation communities. In: E.I.o.I. (Ed.), Technology. EIR, Budapest.

European Commission, 2014a. In: Commission (Ed.), Climate Action: Low Carbon Technologies. EU Commission, Brussels.
European Commission, 2014b. Climate Action: what is the EU Doing? Climate Action European Commission, Brussels.

European Commission, 2015. Agriculture and Climate Change Agriculture and Rura Development. European Union, Brussels.

Faber, A., Hoppe, T., 2013. Co-constructing a sustainable built environment in the Netherlands-Dynamics and opportunities in an environmental sectoral innovation system. Energy Policy 52, 628-638.

FAO, 2010. Climate-smart" Agriculture: Policies, Practices and Financing for Food Security. Adaptation and Mitigation Food and Agricultural Organisation, Rome.

FAO, 2013. Climate-smart Agriculture - Sourcebook in: Nations. In: F.a.A.O.o.t.U. (Ed.). Food and Agriculture Organization of the United Nations, Rome, Italy.

FAO, 2014. FAO Success Stories on Climate-smart Agriculture. In: FOA (Ed.). Food and Agricultural Organisation of the United Nations, Rome.

FAO, EU, 2014. Climate-smart Agriculture - Helping Malawi, Vietnam and Zambia Make the Transition to a "climate-smart" Approach to Agriculture. Food and Agricultural Organisation \& European Union, Brussels, Belgium.

Guerin, T.F., 2001. Why sustainable innovations are not always adopted. Resour. Conservation Recycl. 34, 1-18.

Hall, J., Vredenburg, H., 2003. The Chellenges of Innovating for Sustainable Development Sloan Management Review Fall.

Hoffman, A.J., Henn, R., 2008. Overcoming the social and psychological barriers to Green building. Organ. Environ. 21, 390-419.

Horbach, J., Rammer, C., Rennings, K., 2012. Determinants of eco-innovations by type of environmental impact - the role of regulatory push/pull, technology push and market pull. Ecol. Econ. 78, 112-122.

Huang, Y., Han, W., Lei, Q., Ji, Y., Gao, P., 2013. Driving force and factors influencing changes for farmers' irrigation methods based on an empirical analysis in Shaanxi province. In: American Society of Agricultural and Biological Engineers Annual International Meeting 2013, pp. 4360-4370.

Johnson, M., 2010. Barriers to innovation adoption: a study of e-markets. Indust Manag. Data Syst. 110, 157-174.

Kemp, R., Volpi, M., 2008. The diffusion of clean technologies: a review with suggestions for future diffusion analysis. J. Clean. Prod. 16, S14-S21.

Kolk, A., Levy, D., Pinkse, J., 2008. Corporate responses in an emerging climate regime: the institutionalization and commensuration of carbon disclosure. Eur. Account. Rev. 17, 719-745.

Lockton, D., Harrison, D., Stanton, N., 2008. Making the user more efficient: design for sustainable behaviour. Int. J. Sustain. Eng. 1, 3-8.

Luken, R., Van Rompaey, F., 2008. Drivers for and barriers to environmentally sound technology adoption by manufacturing plants in nine developing countries. J. Clean. Prod. 16, S67-S77.

Luthra, S., Kumar, S., Kharb, R., Ansari, M.F., Shimmi, S.L., 2014. Adoption of smart grid technologies: an analysis of interactions among barriers. Renew. Sustain. Energy Rev. 33, 554-565.

McCarthy, J.J., 2001. Climate Change 2001: Impacts, Adaptation, and Vulnerability: Contribution of Working Group II to the Third Assessment Report of the Intergovernmental Panel on Climate Change. Cambridge University Press.

McCarthy, N., Lipper, L., Branca, G., 2011. Climate-smart Agriculture: Smallholder Adoption and Implications for Climate Change Adaptation and Mitigation. Mitigation of Climate Change in Agriculture Series. FAO, Rome, Italy.

Montalvo, C., 2008. General wisdom concerning the factors affecting the adoption of cleaner technologies: a survey 1990-2007. J. Clean. Prod. 16, S7-S13.

Morand, F., Barzman, M., 2006. European Sustainable Development Policy (19722005): Fostering a Two-dimensional Integration for More Effective Institutions. IDARI working paper, RTD project QLRT-2002-02718. Eco Innovation (Galway, Ireland)/Humbolt University of Berlin, Ireland/Germany.

Nelson, G.C., Rosegrant, M.W., Koo, J., Robertson, R., Sulser, T., Zhu, T., Ringler, C., Msangi, S., Palazzo, A., Batka, M., Magalhaes, M., Valmonte-Santos, R., Ewing, M. Lee, D., 2009. Climate Change: Impacts on Agriculture and Costs of Adaptation. International Food Policy Research Institute, Washington, D.C., USA.

OECD, 2014. Stimulation Demand for Innovation. OECD, Paris, France.

Ratten, V., Ratten, H., 2007. Social cognitive theory in technological innovations. Eur J. Innovat. Manag. 10, 90-108.

Reinstaller, A., 2008. The technological transition to chlorine free pulp bleaching technologies: lessons for transition policies. J. Clean. Prod. 16, S133-S147.

Ren, W., 2015. Climate-smart agriculture: conceptual framework and brief history. In: Plenary Keynote 2 Climate Smart Agriculture: Global Science Conference, March 16th - 18th Montpellier.

Roelofsen, M., Blok, V., Wubben, E., 2015. Maintaining the CSR-identity of sustainable entrepreneurial firms: the role of corporate governance in periods of business growth. In: Frederiksen, C.S., Idowu, S.O., Mermod, A.Y., Nielsen, M.E.J. (Eds.), Corporate Social Responsibility and Governance: Practice and Theory. Springer, Dordrecht.

Rogers, E.M., 1962. Diffusion of Innovations, fourth ed. The Free Press, New York.

Scherr, S., Shames, S., Friedman, R., 2012. From climate-smart agriculture to climatesmart landscapes. Agric. Food Secur. 1, 1-15.

Smith, P., Bustamante, M., Ahammad, H., Clark, H., Dong, H., Elsiddig, E.A., Haberl, H., Harper, R., House, J., Jafari, M., Masera, O., Mbow, C. Ravindranath, N.H., Rice, C.W., Robledo Abad, C., Romanovskaya, A., Sperling, F. Tubiello, F., 2014. 2014: Agriculture, forestry and other land use (AFOLU). In: Edenhofer, O., Pichs-Madruga, R., Sokona, Y., Farahani, E., Kadner, S., Seyboth, K., Adler, A., Baum, I., Brunner, S., Eickemeier, P., Kriemann, B., Savolainen, J., Schlömer, S., von Stechow, C., Zwickel, T., Minx, J.C. (Eds.), Climate Change 2014: Mitigation of Climate Change. Contribution of Working Group III to the Fifth 
Assessment Report of the Intergovernmental Panel on Climate Change. Cambridge University Press, Cambridge, UK and New York, NY, USA.

Smith, P., Martino, D., Cai, Z., Gwary, D., Janzen, H., Kumar, P., McCarl, B., Ogle, S., O'Mara, F., Rice, C., Scholes, B., Sirotenko, O., Howden, M., McAllister, T., Pan, G., Romanenkov, V., Schneider, U., Towprayoon, S., Wattenbach, M., Smith, J., 2008. Greenhouse gas mitigation in agriculture. Philos. Trans. R. Soc. B: Biol. Sci. 363 , 789-813.

Sneddon, J., Soutar, G., Mazzarol, T., 2011. Modelling the faddish, fashionable and efficient diffusion of agricultural technologies: a case study of the diffusion of wool testing technology in Australia. Technol. Forecast. Soc. Change 78, $468-480$.

Taneja, G., Pal, B.D., Joshi, P.K., Aggarwal, P.K., Tyagi, N.K., 2014. Farmer's Preferences for Climate-smart Agriculture: an Assessment in the Indo-Gangetic Plain IFPR Discussion Paper 01337. International Food Policy Research Institute, Washington, D.C., USA.

Tey, Y., Brindal, M., 2012. Factors influencing the adoption of precision agricultural technologies: a review for policy implications. Precis. Agric. 13, 713-730.

Trnka, M., Rotter, R.P., Ruiz-Ramos, M., Kersebaum, K.C., Olesen, J.E., Zalud, Z. Semenov, M.A., 2014. Adverse weather conditions for European wheat production will become more frequent with climate change. Nat. Clim. Change 4 $637-643$.
UNEP, 2013. The Emissions Gap Report 2013. United National Environment Programme, Nairobi, Kenya.

Vermeulen, S.J., Campbell, B.M., Ingram, J.S.I., 2012. Climate change and food systems. Annu. Rev. Environ. Resour. 37, 195-222.

Vishwanath, A., 2009. From belief-importance to intention: the impact of framing on technology adoption. Commun. Monogr. 76, 177-206.

Weber, K.M., Rohracher, H., 2012. Legitimizing research, technology and innovation policies for transformative change: combining insights from innovation systems and multi-level perspective in a comprehensive 'failures' framework. Res. Policy 41, 1037-1047.

Weiss, C., Bonvillian, W.B., 2013. Legacy sectors: barriers to global innovation in agriculture and energy. Technol. Anal. Strat. Manag. 25, 1189-1208.

Wever, R., van Kuijk, J., Boks, C., 2008. User-centred design for sustainable behaviour. Int. J. Sustain. Eng. 1, 9-20.

Wheeler, S.A., 2008. The barriers to further adoption of organic farming and genetic engineering in Australia: views of agricultural professionals and their information sources. Renew. Agric. Food Syst. 23, 161-170.

Wubben, E., Runge, N., Blok, V., 2012. From waste to profit: an interorganisational perspective on drivers for biomass valorisation. J. Chain Netw. Sci. 12, 261-272. 